\title{
Effect of Saccharomyces cerevisiae dried yeast on the meat performance traits and selected indicators of humoral immunity in lambs
}

\author{
Stanisław Milewski ${ }^{1}$, Roman Wójcik ${ }^{2}$, Bożena Zaleska ${ }^{1}$, Joanna Małaczewska ${ }^{2}$, \\ Zenon Tański ${ }^{1}$, Andrzej Krzysztof Siwicki \\ ${ }^{1}$ University of Warmia and Mazury in Olsztyn, Faculty of Animal Bioengineering, \\ Department of Sheep and Goat Breeding, ${ }^{2}$ Faculty of Veterinary Medicine, Department of Microbiology \\ and Clinical Immunology, Olsztyn, Poland
}

Received July 10, 2012

Accepted April 23, 2013

\begin{abstract}
The aim of this study was to determine the effect of Saccharomyces cerevisiae on indicators of meat performance traits in sheep as well as on selected non-specific indicators of humoral and cellular defense. The experiment was performed on 32 suckling Kamieniec lambs divided into two equal groups (control and experimental). Over a period of 60 days, experimental group of lambs were fed a diet supplemented with Saccharomyces cerevisiae dried yeast (the yeast supplement did not change the value of the feed ration). The following meat performance indicators were determined: body weight, daily gains, growth rate, the dimensions of musculus longissimus dorsi sections, skin and subcutaneous fat thickness and fat thickness over the loin "eye" area. Selected indicators of non-specific humoral immunity (lysozyme activity, ceruloplasmin activity, total protein and gamma globulin content) were determined in the blood serum of lambs. Compared to control, yeast administered to the experimental group of lambs significantly increased the values of the analyzed meat performance traits i.e. body weight, growth rate, musculus longissimus dorsi dimensions $(P \leq 0.05)$ and daily gains $(P \leq 0.01)$, pointing to improved muscle development. Lambs fed the yeast showed a significant $(P \leq 0.01)$ increase in lysozyme and ceruloplasmin activity and increased serum concentrations of gamma globulins. Significant differences between the experimental and control groups were not observed only with respect to the serum concentrations of total protein. Suuplementing the lambs' feed with yeast had a positive effect on meat performance traits and indicators of humoral immunity.
\end{abstract}

Non-specific immunity, prebiotic, yeast, meat traits

Rational lamb feeding is a crucial consideration as it may contribute to improving the meat performance of sheep. The end product of optimal quality lamb meat with superior health benefits is obtained through the application of traditional feeding systems with a high share of green forage (Santos-Silva et al. 2002). However, traditional systems are characterized by low production effectiveness. Therefore, attempts are made to develop new solutions that rely on natural conversion of organic feed into lamb meat while ensuring optimal production profitability. One of the most recommended solutions involves the supplementation of animal diets with natural stimulators such as Saccharomyces cerevisiae yeast which has a wide spectrum of activity (Suphantharika et al. 2003). The supplementation of animal feed with yeast can, therefore, have a varied effect, but it usually enhances productivity. Milewski's findings (2009) support the use of Saccharomyces cerevisiae dried brewer's yeast in lamb nutrition. In a study of suckling lambs, the author noted that the administration of the Inter Yeast prebiotic with CJ concentrate in the amount of $50 \mathrm{~g} / \mathrm{kg}$ of feed stimulated the growth rate and muscle development in lambs. Yeast supplementation also had a significant effect on haematological indicators, resulting in higher red blood cell counts and white blood cell counts, increased haemoglobin concentrations and higher lymphocyte percentages in the leukogram, indicating that the preparation actively stimulated the immune system of lambs.

The aim of this study was to determine the effect of dietary Saccharomyces cerevisiae dried brewer's yeast on the meat performance traits and selected indicators of humoral immunity in lambs. 


\section{Materials and Methods}

The experiment was performed on 32 suckling Kamieniec lambs. Lambs aged $30 \pm 3$ days were divided into two groups of 16 animals each (control and experimental); there were 8 females and 8 males in each group. Both groups were identical in terms of type of birth lambs - only single, and were characterized by a similar initial mass of the body.

Uniform feeding standards were applied in both groups in line with lamb nutrient requirements (Osikowski et al. 1998). Diet composition was identical in both groups. In addition to ewe's milk, suckling lambs were fed meadow hay, hay-silage of grass and legumes, and CJ® mixture. Components of this mixture were the following: ground barley $(40 \%)$, ground wheat $(37.5 \%)$, ground maize $(10 \%)$, soybean meal $(10 \%)$, mineral premix $(2 \%)$, fodder chalk $(0.2 \%)$, dicalcium phosphate $(0.2 \%)$ and salt fodder $(0.1 \%)$. These mixture doses, identical for both groups, were increased every 10 days by $0.05 \mathrm{~kg} / \mathrm{animal} /$ day, starting from $0.15 \mathrm{~kg} / \mathrm{animal} / \mathrm{day}$. The lambs from the experimental group were administered the complete CJ mixture with the addition of Saccharomyces cerevisiae preparation (Inter Yeast S INTERYEAST ${ }^{\circledR}$ Krośniewice, Poland) at the dose of $50 \mathrm{~g} / \mathrm{kg}$ of CJ mixture. The quantity of administered feed and leftovers was monitored throughout the experiment.

At the beginning of the study (day 0) and on day 15, 30 and 60 of the experiment, blood was sampled from the jugular vein to determine the selected indicators of humoral immunity in lambs. Ultrasound scanning of meat traits was carried out intravitally without killing the lambs. All procedures related to the animals in this study were approved by the Local Ethics Committee for Animal Experiments in Olsztyn (28/2008).

The following meat performance traits were investigated: body weight at the beginning of the study and on days 30 and 60 of the experiment, daily gains, growth rate at the following time intervals (days 1-30, 31-60 and $1-60$ of the experiment), meatiness mass and fatness determined in vivo by ultrasound examination after 60 days of the experiment. Growth rate was computed based on the following formula:

GRI $=\frac{\text { final body } \text { weight }- \text { inital body weight }}{\left.\frac{1}{2} \text { (inital body weight }+ \text { final body weight }\right)} \times 100 \%$

Dimensions of musculus longissimus dorsi sections, including depth, width, area, skin and subcutaneous fat thickness, fat thickness over the loin "eye" area were determined by ultrasonography. The measurements were performed behind the last rib in accordance with the method proposed by Ślósarz (2004) with the use of an SSD 500 Aloka ultrasound scanner equipped with a $7.5 \mathrm{MHz}$ linear probe.

The humoral immunity of lambs was determined based on lysozyme activity, ceruloplasmin activity, total protein and gamma globulin levels. Whole blood samples were centrifuged for $5 \mathrm{~min}$ at $1,000 \mathrm{~g}$ to separate blood cells from the serum. Lysozyme activity in blood plasma was determined by the turbidimetric method proposed by Parry et al. (1965) and modified by Siwicki and Anderson (1993). Ceruloplasmin activity in blood plasma was determined as described by Siwicki and Studnicka (1986). Serum concentrations of total protein were measured by spectrophotometry applying the method proposed by Lowry et al. (1951) and modified by Siwicki and Anderson (1993). Serum concentrations of gamma globulins were set by the precipitation method as described by Siwicki and Anderson (1993).

The results were processed statistically by a one-factorial analysis of variance in an orthogonal design. The results were processed by ANOVA, and the significance of differences between groups was verified with Duncan's test $(P<0.01$ and $P<0.05)$.

\section{Results}

No significant differences in feed consumption were observed between experimental and control groups in the course of 60 days of the experiment. The above suggests that nutrient intake, including the intake of the studied prebiotic, was similar in both groups.

The body weight of experimental lambs was higher in comparison with control lambs, after both 30 and 60 days of the experiment. It was $1.54 \mathrm{~kg}$ and $2.83 \mathrm{~kg}$ on days 30 and 60 , respectively; however, a significant difference $(P \leq 0.05)$ was determined only after 60 days of the experiment. The above resulted from higher daily gains. The differences in daily gains between the groups were significant in the first 30 days $(P \leq 0.01)$ and consequently throughout the whole period of the experiment $(P \leq 0.05)$. The above affected the growth rate of lambs which was higher in the experimental group; significance were found for the first 30 days and the whole study period, whereas it has not been demonstrated for the period from 31 to 60 days $(P \leq 0.05)$ (Table 1$)$. 


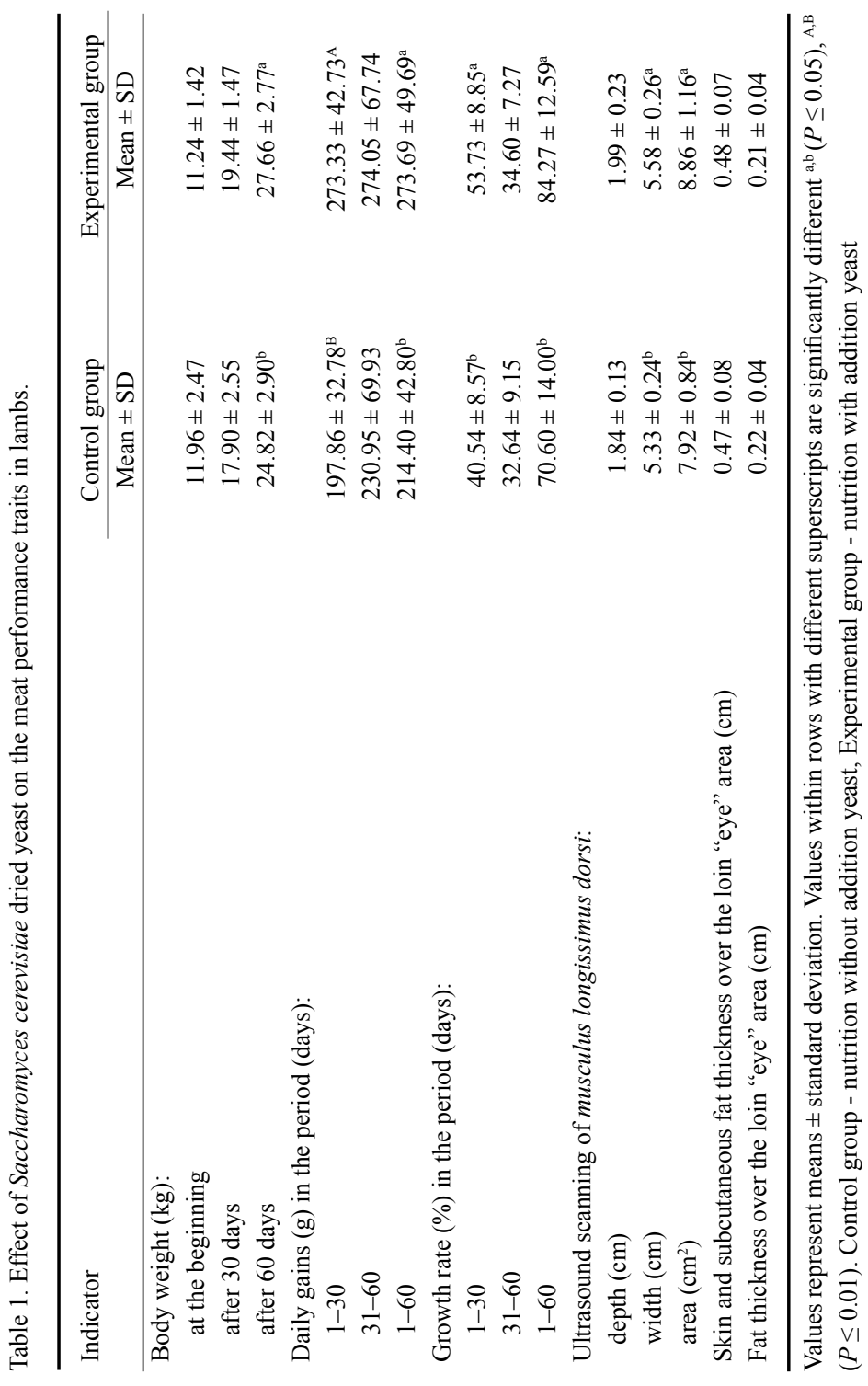

Ultrasound scanning showed that the width and the area of musculus longissimus dorsi were significantly higher in experimental lambs $(P \leq 0.05)$ than in the control group. Measurements of skin and subcutaneous fat thickness, including fat thickness over the loin "eye" area, indicated similar fatness levels in both groups.

As regards the investigated indicators of humoral immunity (Table 2), lysozyme activity and ceruloplasmin activity were significantly higher $(P \leq 0.01)$ in the experimental group on days 15,30 and 60 of the study. Serum concentrations of gamma globulins were also higher in the experimental group than in the control, but differences were significant only on day 30 of the experiment $(P \leq 0.05)$. A significant increase in lysozyme activity, ceruloplasmin activity $(P \leq 0.01)$ and gamma globulin levels $(P \leq 0.05)$ was also noted in the experimental group on days 15,30 and 60 in comparison with day 0 of the experiment. No significant differences between the experimental and control groups were reported with regard to the serum concentrations of total protein throughout the whole period of the study.

\section{Discussion}

The obtained results clearly indicate that the yeast preparation had a stimulating effect on lamb growth and muscle development without causing excessive carcass fatness. The 


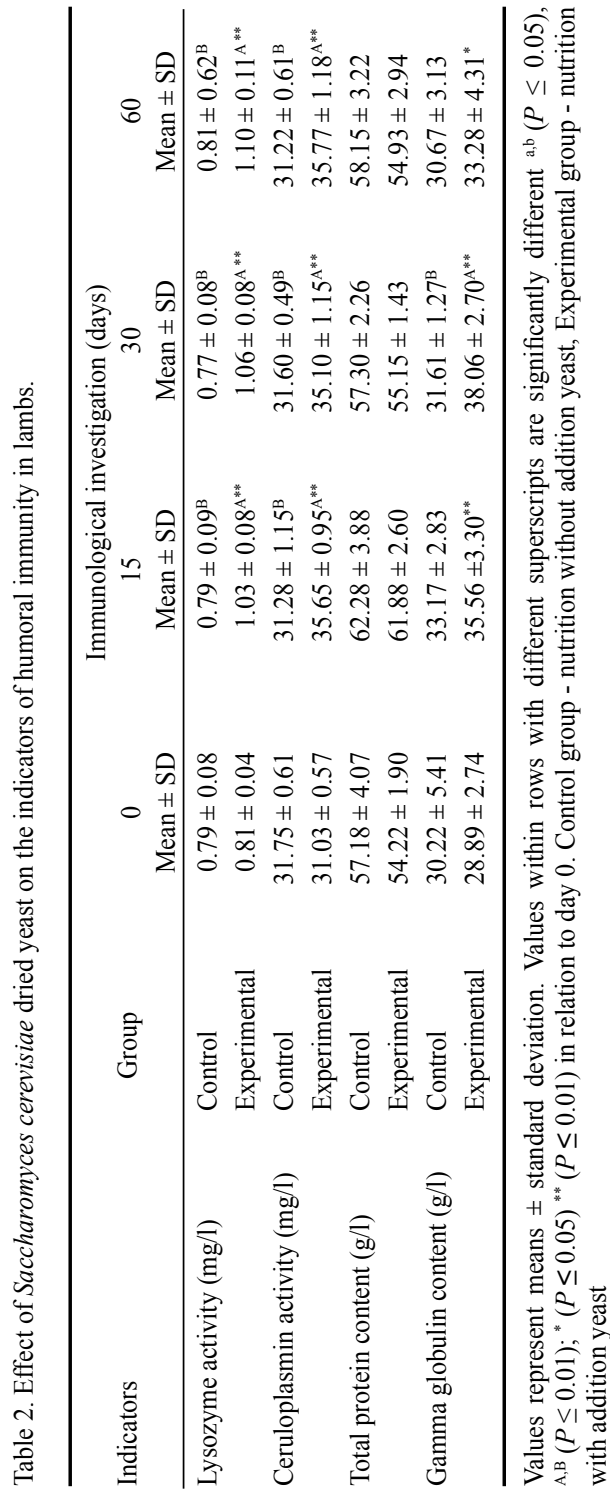

meat performance indicators noted in this study correspond to the earlier findings of Milewski (2009). These results are due to the prebiotic properties of the applied preparation. Yeast could affect metabolic processes in the rumen and, consequently, the growth rate of lambs. Supporting evidence for the above observation can be found in a study of calves carried out by Dobicki et al. (2005). The authors reported that the Inter Yeast feed supplement containing Saccharomyces cerevisiae dried brewer's yeast caused significant changes in the rumen microbial flora by lowering protozoon counts and increasing the size of bacterial populations responsible for the course of ruminal processes. The above enhanced the flow of bacterial and feed protein, stimulating lamb growth. Dobicki et al. (2007) demonstrated the stimulating effect of dried yeast on milk production.

The results of experiments conducted on cattle (Dobicki et al. 2005, 2007) and sheep (Milewski 2009) indicate that yeast preparations have a favourable effect on the animals' immune system. The immunostimulating effect of Saccharomyces cerevisiae dried brewer's yeast was ascribed to the activity of $\beta-1,3 / 1,6$-D-glucans and mannan-oligosaccharides presented in yeast cell walls (Kuprechtova and Illek 2006; Milewski et al. 2007; Wójcik et al. 2007). This mechanism involves the stimulation of immunocompetent cells, mainly by $\beta-1,3 / 1,6-D$-glucans (Xiao et al. 2004; Siwicki et al. 2004). Beta-glucans activate intercellular defense mechanisms where macrophages, T cells and NK cells play the key role (Benda et al. 1989; Demir et al. 2007). A study on calves (Szymańska-Czerwińska et al. 2007) showed that the administration of a feed supplement containing a combination of $\beta$-glucans and $\beta$-mannans significantly increased IL-1 interleukin activity, leading to quantitative changes in lymphocyte subpopulations. The specific ability of mannanoligosaccharides to bind selected pathogenic microbes has a profound effect on the organism's health status. Mannose blocks microbial lectins and prevents pathogens from colonizing the host's gastrointestinal system (Sharon 2008). Oligosaccharides are not degraded by the digestive enzymes of the small intestine, therefore, the attached pathogens are more easily excreted (Spring et al. 2000).

It may be concluded that the administration of Saccharomyces cerevisiae dried brewer's yeast to suckling lambs has a stimulating effect on their meat performance traits and 
lysozyme and ceruloplasmin activity. Dried yeast Inter Yeast ${ }^{\circledR}$ showed positive stimulating effect without the risk of toxicity and recommended dose should be $50 \mathrm{~g} / \mathrm{kg}$ of nutritive fodder.

\section{References}

Benda V, Petrovský E, Hampl A, Kalová J 1989: Glucan stimulates antibody response to a T-dependent antigen in chickens. Acta Vet Brno 58: 345-351

Demir G, Klein HO, Mandel-Molinas N, Tuzuner N 2007: Beta glucan induces proliferation and activation of monocytes in peripheral blood of patients with advanced breast cancer. Int J Immunopharmacol 7: 113-116

Dobicki A, Preś J, Luczak W, Szyrner A 2005: Influence of dried brewery's yeast on body weight gains, physiological and biochemical indicators of blood and development of the rumen micro-organisms in calves. Medycyna Wet 61: 946-949

Dobicki A, Preś J, Zachwieja A, Mordak R, Jakus W 2007: Influence of yeast preparations on chosen biochemical blood parameters and the composition of cow milk. Medycyna Wet 63: 955-959

Kuprechtova D, Illek J 2006: Effect of mannan oligosaccharides supplemented via milk replacer on the immune status and growth of calves. Slov Vet Zbr 43: 311-313

Lowry OH, Rosebrough NJ, Farr AL, Randall R 1951: Protein measurements with the folin phenol reagent. J Biol Chem 193: 265-275

Milewski S 2009: Effect of yeast preparations Saccharomyces cerevisiae on meat performance traits and blood hematological indices in suckling lambs. Medycyna Wet 65: 51-54

Milewski S, Wójcik R, Małaczewska J, Trapkowska S, Siwicki AK 2007: Effect of $\beta$-1,3/1,6-D-glucan on meat performance and non-specific humoral defense mechanisms in lambs. Medycyna Wet 63: 360-363

Osikowski M, Porębska W, Korman K 1998: Feeding standards of cattle and sheep in the traditional system. Inst Zoot, Kraków, ed. XII, pp. 29-57

Parry RM, Chandau RC, Shahani RM 1965: A rapid and sensitive assay of muramidase. Proc Soc Exp Biol Med 119: $384-386$

Santos-Silva J, Bessa RJB, Santos-Silva F 2002: The effect of genotype, feeding system and slaughter weight on the quality of light lambs. Livestok Prod Sci 77: 187-194

Sharon N 2008: Lectins: past, present and future. Biochem Soc Trans 36: 1457-1460

Siwicki AK, Studnicka M 1986: Ceruloplasmin activity in carp (Cyprinus carpio). Bamidgeh 38: 126-129

Siwicki AK, Anderson DP 1993: Immunostimulation in fish: Measuring the effects of stimulants by serological and immunological methods. US Fish Wildl Service-IFI pp. 1-17

Siwicki AK, Kazuń K, Głąbski E, Terech-Majewska E, Baranowski P, Trapkowska S 2004: The effect of beta1.3/1.6-glucan in diets on the effectiveness of anti-Yersinia ruckeri vaccine - an experimental study in rainbow trout (Oncorhynchus mykiss). Pol J Food Nutr Sci 54: 59-61

Ślósarz P. 2004: Ultrasound measurements of lambs meatiness and fatness in prediction of breeding value in white-headed mutton sheep. Rocz AR Poznań, Rozpr Nauk. 1: 1-73

Spring P, Wenk C, Dawson KA, Newman KE 2000: The effects of dietary mannan-oligosaccharides on cecal parameters and the concentrations of enteric bacteria in the ceca of salmonella-challenged broiler chicks. Poult Sci 79: 205-211

Suphantharika M, Khunrae P, Thanrdkit P, Verduyn C 2003: Preparation of spent brewer's yeast $\beta$-glucans with a potential application as an immunostimulant for black tiger shrimp, Penaeus monodon. Biores Technol 88: $55-60$

Szymańska-Czerwińska M, Bednarek D, Kowalski C 2007: Effect of prebiotic additives on interleukin 1 activity and alternations of peripheral blood leukocyte subpopulations in calves. Medycyna Wet 63: 1591-1594

Wójcik R, Małaczewska J, Trapkowska S, Siwicki AK 2007: Influence of $\beta-1,3 / 1,6-D$-glucan on non-specific cellular defence mechanisms in lambs. Medycyna Wet 63: 84-86

Xiao Z, Trincado CA, Murtaugh MP 2004: Beta-glucan enhancement of T cell IFN gamma response in swine. Vet Immunol Immunopathol 102: 315-320 